\title{
Effect of Dust Storm Intensity Variations on Total
}

\section{Path Attenuation Prediction}

\author{
Elfatih A. A. Elsheikh, Islam Md. Rafiqul, Senior Member, IEEE, Mohamed Hadi Habaebi, Senior Member, IEEE, \\ Alhareth Zyoud, Member, IEEE, F. M. Suliman, Member, IEEE, E.I. Eltahir, and Nadir W. A
}

\begin{abstract}
This paper proposes a novel dust-storm total path attenuation prediction model. This model is formulated as a function of specific attenuation $(\mathrm{dB} / \mathrm{km})$ and the effective distance, which considers the non-uniform dust storm intensity variations throughout the link. The effective distance is obtained as a combination of the total link distance and the reduction factor. The reduction factor is developed based on the modeled 2-D structure of the observed dust storm characteristics. A measurement campaign of atmospheric characteristics, their properties, and effects on several microwave links operated in Khartoum-Sudan was conducted. In an earlier report, an empirical dust storm attenuation prediction model was proposed based on short-distance links by assuming uniform dust storm intensity variations. However, it was observed that the dust intensity varies with the distance, which affects total attenuation, and this issue is not addressed yet. One year measurement on the $6.2 \mathrm{~km}$ and $7.6 \mathrm{~km}$ long microwave links operating at $21.2 \mathrm{GHz}$ and $14.5 \mathrm{GHz}$ are used to validate the proposed dust storm total path attenuation model.
\end{abstract}

Index Terms - Dust Storm; Attenuation Prediction; Microwave Propagation, Dust Intensity Variation.

\section{INTRODUCTION}

$\mathrm{D}$ UST and sand storms are frequently experienced in many of the world's dry regions. Recent investigations have shown that dust storms strike different parts of the world for a significant time annually, causing a wide area to be covered with dust and sand. This phenomenon impacts the economy, human health, livestock populace, transportation means, and telecommunication services, where strong winds may spread out dust storms to cover vast areas [1].

The authors extend their appreciation to the Deanship of Scientific Research at King Khalid University for funding this work through Research Group Program under grant number GRP/310/42. Elfatih E. A. Elsheikh (corresponding author e-mail: eelsheikh@kku.edu.sa) and F. M. Suliman (email: fmsuliman@kku.edu.sa) are with the Department of Electrical Engineering, College of Engineering, King Khalid University, Abha, Saudi Arabia, 61421

Islam Md. Rafiqul (e-mail: rafiq@iium.edu.my) and Mohamed H. Habaebi (e-mail: habaebi@iium.edu.my) are with the Department of Electrical and Computer Engineering, IIUM, Kuala Lumpur, Malaysia.

Alhareth Zyoud (e-mail: alhmtz@gmail.com) is with the Department of Electrical and Computer Engineering, Birzeit University, Birzeit, Ramallah, Palestine

E. I. Eltahir (e-mail: eltahirelnayal@gmail.com) is with the Department of Applied Physics \& Mathematics Omdurman Ahlia University Omdurman, Sudan

Nadir W. A. (email: aminnadir2@gmail.com) is with College of Computer Science and Mathematics, University of Bahri, Khartoum, Sudan.
A conclusion has been drawn that absorption and scattering are negligible for frequencies of less than $10 \mathrm{GHz}$. However, for frequency higher than $10 \mathrm{GHz}$, significant effects can be observed [2]. Currently, the radio spectrum is congested, and increasing demand for high data rates makes hopping to higher frequencies inevitable. As the frequency increases, wave-length quickly approaches the dust particle size; hence the effect of scattering increases exponentially, especially at severe dust storms [3-4].

Deployment of the $5^{\text {th }}$ generation telecommunication systems and the emergence of the Internet of Things (IoT) impose a challenge to study the effects of these storms on Microwaves and millimeter waves with particular applications in the areas of antenna theory, particle characteristics, and microwave systems performance.

Numerous methods were developed based on different approaches to estimate attenuation caused by sand dust storms. Analytical, numerical, and experimental methods are introduced to calculate the attenuation at different accuracy levels [5 -13]. However, analytical and mathematical models are based on certain theoretical assumptions; they do rely on measured dust particle characteristics in attenuation prediction [14-15]. A recent measurement campaign of atmospheric characteristics, their properties, and effects on several microwave links operated in Khartoum-Sudan was conducted [12]. All analytical, numerical, and experimental methods were unable to predict the measurement and underestimated significantly $[12,16]$. In the previous article, an empirical dust storm attenuation prediction model in $\mathrm{dB} / \mathrm{km}$ was proposed based on dust storm attenuation measurements on two microwave links of 2.6 and $2.8 \mathrm{~km}$ operated at $14.4 \mathrm{GHz}$ and $21.3 \mathrm{GHz}$, respectively. The measured attenuation was utilized to calculate $\mathrm{dB} / \mathrm{km}$ by assuming uniform dust storm intensity variations along the links [12].

Attenuation is estimated in $\mathrm{dB} / \mathrm{km}$ by all contemporary models, considering that the dust storm is uniformly distributed across the Microwave link [17]. However, the uniform distribution of the dust storm is far from the real environment, which affects total attenuation, and this issue is not addressed in literature yet. The assumption of uniform distribution of the dust storm intensity along the microwave path can overestimate the predicted attenuation for longer path length links. In reality, the severity of the dust storm intensity varies across the Microwave path [11].

Goldhirsh has attempted to characterize the dust storm 2D structure by proposing a $2 \mathrm{D}$ exponential model that relates the dust storm path attenuation to the visibility across the link [11]. 
Goldhirsh modeled a dust storm as a circularly symmetric ellipse shape, having minimum visibility at its center, and increases exponentially radially up to a fixed maximum visibility threshold level. The proposed model constituted a convenient analytical tool that provides reasonable estimates of dust storm intensity variations across the link. In [18], researchers extended Goldhirsh's model by introducing a method to calculate the effective horizontal distance.

In this paper, a novel dust-storm total path attenuation prediction model is proposed as a multiplication of specific attenuation and the effective distance considering non-uniform dust storm intensity variations throughout the link. A recent measurement campaign of atmospheric characteristics and their effects on the $6.2 \mathrm{~km}$ and $7.6 \mathrm{~km}$ long microwave links operating at $21.2 \mathrm{GHz}$ and $14.5 \mathrm{GHz}$ are used to validate the proposed dust storm total path attenuation model.

\section{MODELING DUST STORM INTENSITY VARIATIONS}

\section{A. Development of the Reduction Factor}

Goldhirsh 2-D dust storm model provided a simple estimation of the dust storm visibility structure, as shown in Equation (1) [11].

$$
V=V_{o} \exp \left(\frac{l}{l_{o}}\right)
$$

Where

$l$ is the radial distance from the center of the storm, $V_{o}$ is the point of the minimum visibility, $l_{o}$ is the characteristic radial distance over which minimum visibility increases by a factor of $\exp (1)$.

Attenuation of electromagnetic radiation $\left(A_{T}\right)$ through a Microwave link of length $d$ via a medium of precipitation is expressed as follows [19]:

$$
A_{T}=\int_{0}^{d} A_{s} \cdot d x(d B)
$$

Where $A_{s}(\mathrm{~dB} / \mathrm{km})$, the specific attenuation from the dust precipitating particles can be calculated using Elsheikh empirical model as follows [12]:

$$
A_{s}=\left(a \times(V)^{b}\right) \times\left(c \times(f)^{d}+e\right)(\mathrm{dB} / \mathrm{km})
$$

Where

$\mathrm{V}$ : visibility in $\mathrm{km}$

$a=0.6301$

$b=-1.123$

$f:$ frequency in $\mathrm{GHz}$.

c, d,e : Parameters represent imaginary part of dielectric

constant at different frequencies and moisture as in [12].

For the development, the path reduction factor $(R)$, the following points are assumed. a. The minimum visibility point $\left(V_{o}\right)$ is at the center of the dust storm.

b. The specific attenuation $\left(A_{s}\right)$ is predicted at minimum visibility $\left(V_{o}\right)$.

The specific attenuation $A_{s}$ can be estimated at the point of minimum visibility $\left(V_{o}\right)$ is as follows:

$$
A_{s_{o}}=\left(a \times\left(V_{o}\right)^{b}\right) \times\left(c \times(f)^{d}+e\right) \quad(\mathrm{dB} / \mathrm{km})
$$

On the other hand, the total attenuation experienced by the whole link $\left(A_{t}\right)$ can be obtained by substituting Equation (1) and Equation (3) in Equation (2) as follows:

$$
A_{T}=\int_{0}^{d}\left[\left(a \times\left(V_{o} \times \exp \left(\frac{l}{l_{o}}\right)\right)^{b}\right) \times\left(c \times(f)^{d}+e\right)\right] \cdot d x(\mathrm{~dB})
$$

Where

$V$ the visibility variations as modeled in Equation (3)

$l$ radial distance from the minimum visibility point.

$l_{o}$ The characteristic radial distance over which the minimum visibility increases by a factor of $\exp (1)$.

Based on the assumption of symmetrically distributed dust storm intensity from the center (minimum visibility point, hence:

$$
A_{T}=\int_{-l_{1}}^{l_{1}}\left[\left(a \times\left(V_{o} \times \exp \left(\frac{l}{l_{o}}\right)\right)^{b}\right) \times\left(c \times(f)^{d}+e\right)\right] \cdot d l(\mathrm{~dB})
$$

Where $\mathrm{d}=2^{\times} l_{1}$

Therefore, Equation (6) can be re-expressed as follow

$A_{T}=2 \times \int_{0}^{l_{1}}\left[\left(a \times\left(V_{o} \times \exp \left(\frac{l}{l_{o}}\right)\right)^{b}\right) \times\left(c \times(f)^{d}+e\right)\right] . d l(\mathrm{~dB})(7)$

Where

$l_{l}$ is the radial distance from the minimum visibility point $\left(V_{o}\right)$

Alternatively, the total attenuation $A_{T}$ can be expressed as :

$$
A_{T}=A_{s_{o}} \times d_{e f f} \quad(\mathrm{~dB})
$$

Where

$$
d_{\text {eff }}=d \times R \quad \mathrm{~km}
$$

$\mathrm{A}_{\mathrm{T}}$ is the total attenuation throughout the microwave link.

$A_{s_{o}}$ Specific attenuation in $\mathrm{dB} / \mathrm{km}$ calculated at $V_{o}$.

$d_{\text {eff }}$ effective distance

$d$ the microwave link length in $\mathrm{km}$ where $\mathrm{d}=2^{\times} l_{l}$.

$R$ is the reduction factor which reflects the dust storm intensity variations. 
Substituting the values of the specific attenuation $A_{s_{0}}$ and total attenuation $\mathrm{A}_{\mathrm{T}}$ in Equation (8a), and solving for $R$ gives:

$$
R=\frac{\int_{0}^{l_{1}}\left(\exp \left(\frac{l}{l_{o}}\right)\right)^{b} \cdot d l}{l_{1}}
$$

Let $b=-1.123$ [12], Equation (9) can be re-expressed as:

$$
R=\frac{1}{1.123} \times \frac{l_{o}}{l_{1}}\left[1-\left(e^{-1.123 \times\left(l / l_{o}\right)}\right)\right]
$$

Hence, a reduction factor is proposed based on the 2-D visibility model. The proposed reduction factor is a step forward that enables the calculation of total path attenuation; a longer length microwave link might suffer.

\section{B. Estimation of the Reduction factor at different dust storm intensities}

Goldhirsh observed a severe dust storm on May $9^{\text {th }} 1990$, visibility during the storm is estimated to be smaller than $5 \mathrm{~m}$, and $100 \mathrm{~m}$ measured at two different points simultaneously. The corresponding values of the minimum visibility and the characteristic radial distance are found to be $\mathrm{V}_{\mathrm{o}}=1.84 \times 10^{-3}$ and $l_{o}=9.26 \mathrm{~km}$, respectively. This indicates the worst case scenario in dust intensity variations which has significant impact on the reduction factor. Substituting the values of $\mathrm{V}_{\mathrm{o}}=1.84^{\times} 10^{-3}$ and $l_{o}=9.26 \mathrm{~km}$ in Equation (1) produces the modeled visibility structure of the observed dust storm in Khartoum $(5 \mathrm{~m}-100 \mathrm{~m})$, as shown in Figure 1.

From Figure 1, it is clear that at lower visibility (visibility < $5 \mathrm{~m})$, the resulted radial distance is approximately $9.25 \mathrm{~km}$. Whereas, for higher visibility $(5<$ visibility $<100 \mathrm{~m})$, the corresponding radial distance is equal to $37 \mathrm{~km}$. Therefore, visibility variations of the dust storm are directly proportional to the radial distance covered by the storm. Hence, different values of the parameters $V_{o}$ and $l_{o}$ reflect different visibility structures of the dust storm; consequently, the portion of the radial distance has been covered by the storm.

Moreover, the proposed reduction factor $(R)$ shown in Equation (10), is a function of the characteristic radial distance $l_{o}$ and the total link length $(d)$. Different values of $l_{o}$ and $d$ produce a different reduction factor, as shown in Figure 2.

Figure 2 shows the portion of the link covered by the dust storm at different dust storm structures represented by the curves with different $l_{o}$ values. As the link length $(d)$ increases, the portion of the link covered by the dust is reduced. For example, a link of $2 \mathrm{~km}$ length at a characteristic radial distance of $l_{0}=9.25 \mathrm{~km}$ (Goldhirsh measurement) [11], reduction factor value is $\mathrm{R}=0.9417$ (almost the entire link is covered), while for the same value of $l_{o}$, a link of $50 \mathrm{~km}$ length, reduction value $\mathrm{R}$ reduced to 0.3139 (only $31 \%$ of the link is covered). On the other hand, for another dust storm structure where $l_{0}=30 \mathrm{~km}$, a link with $2 \mathrm{~km}$ length, the reduction factor value $\mathrm{R}=0.9815$, whereas for the same $l_{o}$ value, a link with $50 \mathrm{~km}$ length, the reduction factor reduced to $\mathrm{R}=0.6494$ (only $65 \%$ of the link is covered).

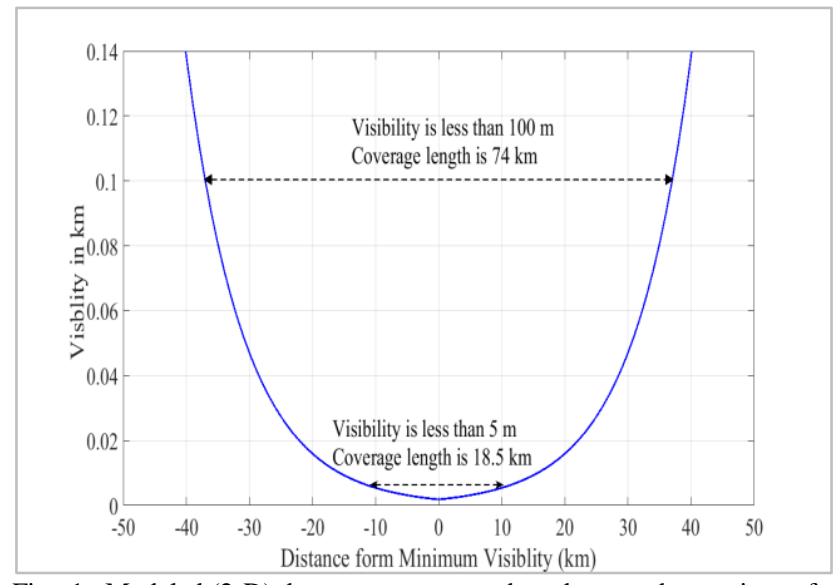

Fig. 1. Modeled (2-D) dust storm structure based on an observations of a dust storm in Khartoum on 9th May, 1990 [11]

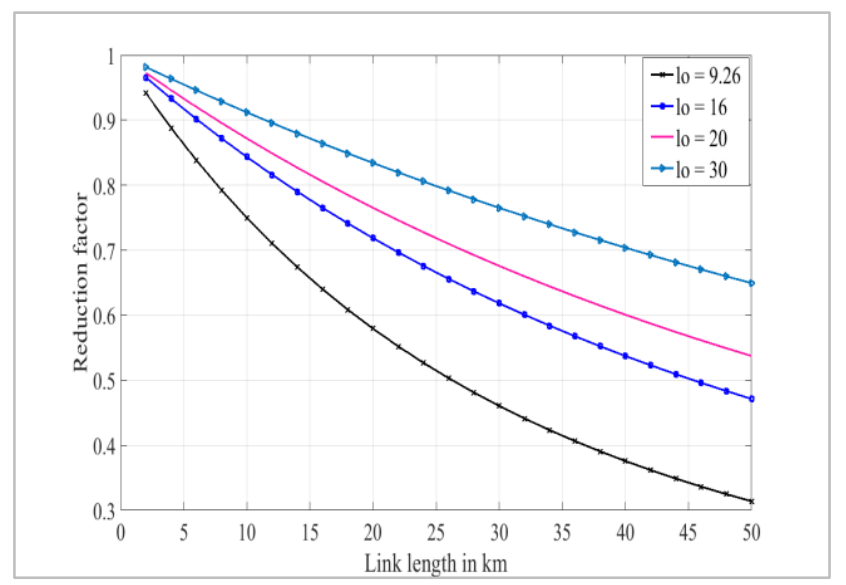

Fig.2.Variations of values of reduction factor with link lengths at different dimensions of dust storm visibility structures

Hence, for both visibility structures with $l_{o}=9.25 \mathrm{~km}, l_{o}=30 \mathrm{~km}$ evident variations of dust intensity exists along the Microwave link. Decay in visibility along the link covered by the storm is apparent for both dust storm structure where $l_{0}=9.25 \mathrm{~km}$ and $l_{0}=30 \mathrm{~km}$ as the link length increases.

\section{The total Path attenuation model}

A total path attenuation prediction model is developed by taking the product of two components. The first component is the empirical specific attenuation prediction model $(\mathrm{dB} / \mathrm{Km})$ [12]. The second component is the effective length covered by the dust storm. The effective path is simply the total link length $(d)$ multiplied by a reduction factor $(R)$. Reduction factor $(\mathrm{R})$ is a ratio that accommodates horizontal dust storm intensity variations along the Microwave link.

Hence, Equation (2) can be re-expressed in equations (8a) and (8b).

Where,

$A_{s}$ is as given in equation (3)

$\mathrm{R}$, is as given in equation (10)

$d_{\text {eff }}$ effective distance in $\mathrm{km}$ as in (8b), $d$ Total link length in $\mathrm{km} . A_{T} \quad$ Total attenuation in $\mathrm{dB}, A_{s}$ specific attenuation in $\mathrm{dB} / \mathrm{km}, R$ adjustment factor, $l_{l}$ is the radial distance from the 
center of the storm, $l_{o}$ is the characteristic radial distance over which the minimum visibility increases by a factor of $\exp (1)$.

Hence, based on Goldhirsh measurement for visibility range $5 \mathrm{~m}$ to $100 \mathrm{~m}$; the value of $l_{o}$ is found to be $l_{o}=9.26 \mathrm{~km} \mathrm{[11]}$. Therefore, $l_{o}$ value is substituted as $9.26 \mathrm{~km}$ in equation (10).

Therefore, the total path attenuation due to the dust storm is estimated as in Equation (11):

$$
\begin{aligned}
& A_{T}=\left(\left(a \times V^{b}\right) \times\left(\left(c \times f^{d}\right)+e\right)\right) \times \\
& \left(d \times\left(\frac{1}{1.123} \times \frac{9.26}{l_{1}}\left[1-\left(e^{-1.123 \times\left(\frac{l_{1}}{l_{o}}\right)}\right)\right]\right)\right) \mathrm{dB}
\end{aligned}
$$

\section{EXPERIMENTAL SETUP, DATA COLLECTION, AND}

\section{PROCESSING}

The monitoring system includes two microwave links, a meteorological station, and a set of data acquisition hardware. The microwave links were MOBLOOL_JREEFSHAREG and BIA-2_MANCHIA, which were relatively long Microwave links operating at $21.2 \mathrm{GHz}$ and $14.5 \mathrm{GHz}$ with link lengths of $6.2 \mathrm{Km}$ and $7.6 \mathrm{Km}$, respectively (shown in blue dashed lines in Figure 3). The links were located in north and south-east from Khartoum International Airport (illustrated in red arrows in Figure 3) where a metrological station named as automatic weather station (AWS) was installed.

\section{A. Data Collection}

Optical visibility is monitored using the Vaisala Transmissometer equipment LT31; LT31 transmissometer is used for measuring the atmospheric transmittance at visibility deterioration (fog, rain, dust). LT 31 transmissometer measures the transmitted light signal through the atmosphere. It consists of a light-transmitting and receiving optically aligned units, which are located in predetermined places with $30 \mathrm{~m}$ separations. Degradation in the visibility across the predetermined path results in decreased signal intensity as it reaches the receiver. Therefore, LT31 can directly compare the transmitted and received light signals.

It makes calculations for the mean extension coefficient, including both scattering and absorption., LT31 sensor can measure meteorological optical range (MOR) or visibility with the accuracy of $\pm 3 \%$ for a range of $10 \mathrm{~m}-10000 \mathrm{~m}$ with 1 minute collection time [20].

Table I and Table II, respectively, provide a detailed description of the Microwave connections MOBLOOL JREEFSHAREG and BIA-2 MANCHIA. Figure 3 displays the locations of the meteorological station and the microwave link-additionally, temperature, relative humidity, wind speed, and wind direction sensors were monitored simultaneously [20]. Over 22 dust storm events were witnessed in Khartoum city during the oneyear experimental period.

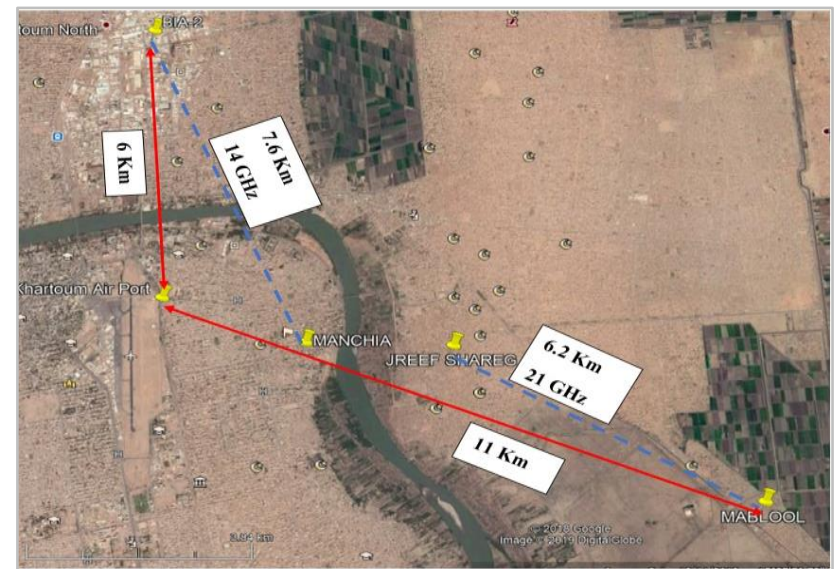

Fig. 3. Location map of MOBLOOL_JREEFSHAREG Microwave link and the weather station

All atmospheric parameters were recorded as with their corresponding transmitted and the received signals during the year starting from $1^{\text {st }}$ June 2014 to $31^{\text {st }}$ May 2015.

Table I

MABLOOL - JAREEF SHARIG MICROWAVE LINK

\begin{tabular}{lll}
\hline \hline Parameters & MABLOOL & JAREEF SHARIG \\
\hline RX Frequency $(\mathrm{MHz})$ & 21253.25 & 22453.25 \\
Polarization & Horizontal & Horizontal \\
Antenna diameter & $0.6 \mathrm{~m}$ & $0.6 \mathrm{~m}$ \\
Antenna gain & $40.5 \mathrm{dBi}$ & $40.5 \mathrm{dBi}$ \\
Antenna height & $25 \mathrm{~m}$ & $21 \mathrm{~m}$ \\
TX Power & $12 \mathrm{dBm}$ & $12 \mathrm{dBm}$ \\
\hline \hline
\end{tabular}

Table II

BIA-2-MANCHIA MICROWAVE LINK

\begin{tabular}{lll}
\hline \hline Parameters & BIA-2 & MANCHIA \\
\hline RX Frequency $(\mathrm{MHz})$ & 14502.75 & 14992.75 \\
Polarization & Vertical & Vertical \\
Antenna diameter & $1.2 \mathrm{~m}$ & $1.2 \mathrm{~m}$ \\
Antenna gain & $42.50 \mathrm{dBi}$ & $42.50 \mathrm{dBi}$ \\
Antenna height & $25 \mathrm{~m}$ & $36 \mathrm{~m}$ \\
TX Power & $18.5 \mathrm{dBm}$ & $18.5 \mathrm{dBm}$ \\
\hline \hline
\end{tabular}

\section{B. Data Processing}

The one-year data collected from the Vaisala Transmissometer LT31 was analyzed using MATLAB. A cumulative distribution function of measured optical visibility is generated.

The following steps have been taken to extract and process the received signal level data:

1. Zero readings and unrecorded data have been deleted to prepare the data for the processing.

2. From the data, it can be noticed clearly that the received signal level for $6.2 \mathrm{~km}$ link at $21 \mathrm{GHz}$ was varying around -40 $\mathrm{dBm}$ before dust storm started and dropped to $-54 \mathrm{dBm}$ during storm as shown in Figure 4.

3. Hence, a threshold of the received signal level is calculated by averaging measured values during clear weather with high visibility period. 
4. The dust storm attenuation is calculated by subtracting the received signal level $(\mathrm{dBm})$ from threshold $(\mathrm{dBm})$ and expressed in decibel (dB).

5. Consequently, all of the received signal levels during dust storms have been processed to produce the attenuation as shown in Figure 5.

6. The accumulated attenuation data measured for MABLOOL - JAREEF SHARIG Microwave link has been processed over 1 year to produce the Complementary Cumulative Distribution Function (CCDF) using Matlab. The produced Complementary Cumulative Distribution Function (CCDF) is shown in Figure 6 for $6.2 \mathrm{Km}$ link at $21.2 \mathrm{GHz}$.

7. Same procedures have been followed for BIA-2MANCHIA Microwave Link $7.6 \mathrm{~km}$ operating at $14.5 \mathrm{GHz}$ to produce the attenuation (CCDF) as illustrated in Figure 7.

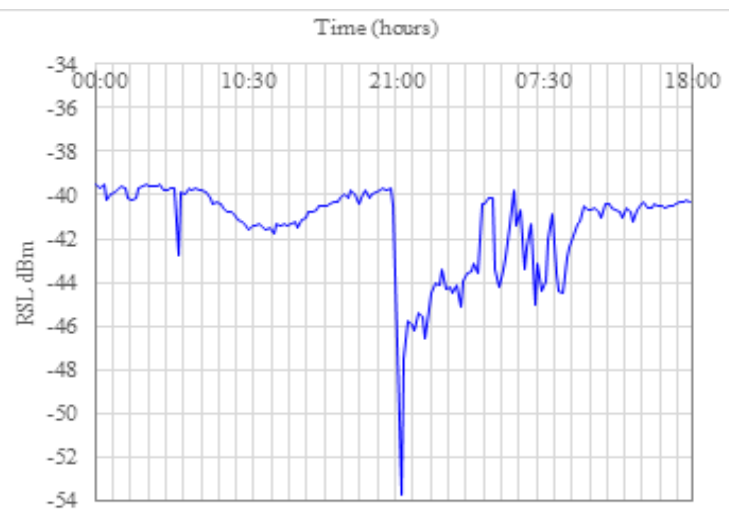

Fig. 4 Measured received signal level for MABLOOL-JEREEF link on 6-7th June 2014 at Khartoum

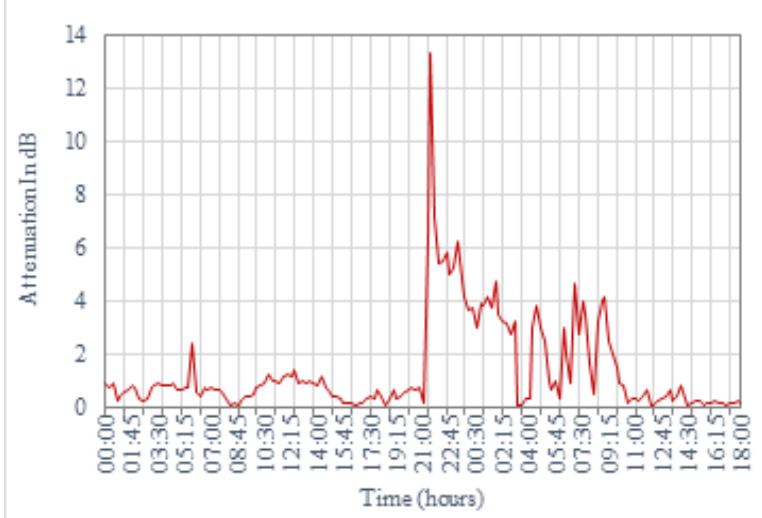

Fig. 5. Measured attenuation for MABLOOL-JEREEF link on 6-7th June 2014 at Khartoum.

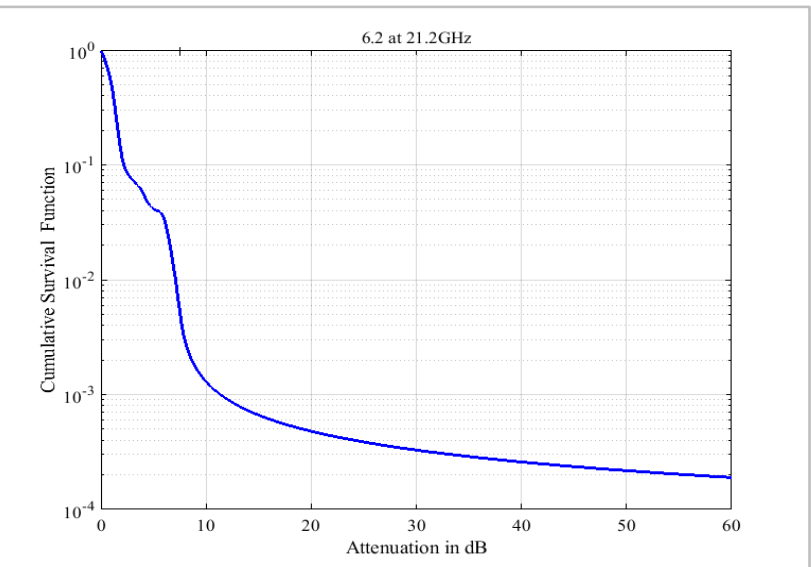

Fig. 6. One-year measured total attenuation throughout the Microwave link for $6.2 \mathrm{Km}$ link at $21.2 \mathrm{GHz}$.

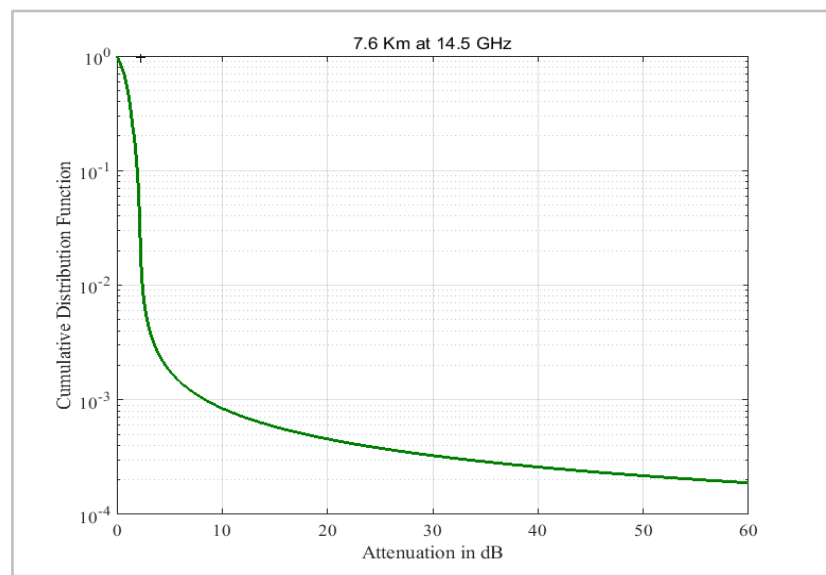

Fig.7. One year measured total attenuation throughout the microwave link for a $7.6 \mathrm{Km}$ link at $14.5 \mathrm{GHz}$.

The dust storm attenuation is calculated by subtracting the received signal level $(\mathrm{dBm})$ from the threshold $(\mathrm{dBm})$ and expressed in decibel $(\mathrm{dB})$. The receivers sensitivities for both of the microwave links were $-100 \mathrm{dBm}$, while receive signal levels without dust storms were varied around $-40 \mathrm{dBm}$. Hence the minimum $60 \mathrm{~dB}$ dynamic ranges were achieved for both links. $1^{\text {ST }}$

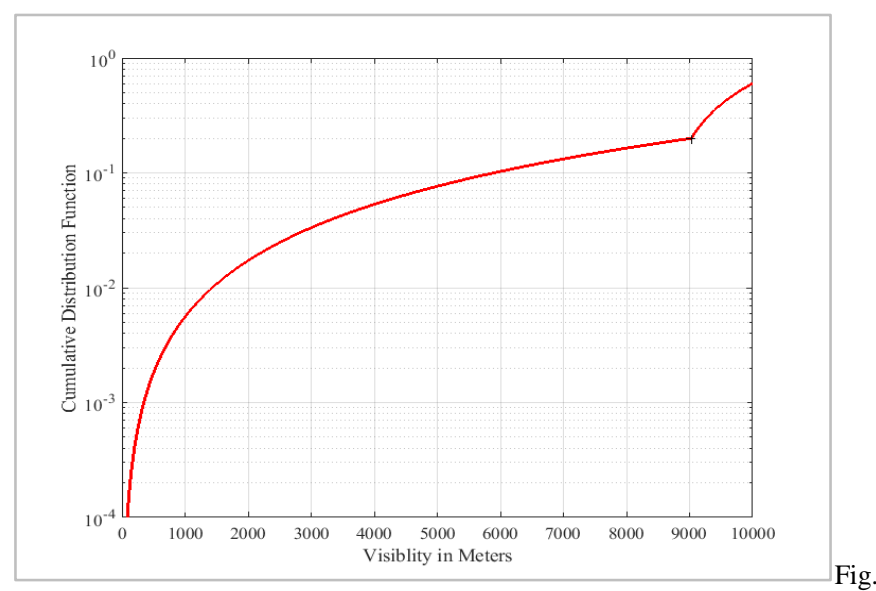

8. Cumulative distribution of measured visibility from June $1^{\text {st }}, 2014$ to May $31^{\text {st }}, 2015$, in Khartoum. 
Figure 8 displays the percentage of the time of year, where optical visibility was decreased below $10,000 \mathrm{~m}$ due to Khartoum dust storms. A threshold of the received signal level is calculated by averaging measured values during clear weather with a high visibility period.

\section{VAlidation of the PROPOSED Model}

The predicted attenuation using the proposed total path attenuation model is compared with the measured attenuation of MABLOOL - JAREEF SHARING, with both $6.2 \mathrm{~km}$ and 7.6 $\mathrm{km}$ links operating at $21.2 \mathrm{GHz}$ and $14.5 \mathrm{GHz}$, respectively. Figure 9 and Figure 10 show the comparison between the measured and total path attenuation predicted by the proposed equation (11). Good agreement between measurement and prediction can be observed in most of the visibility levels on both of the links. From Figure 7, the prediction underestimates at low and high visibility levels, while good agreement in the middle for 21.2 GHz. From Figure 8, the prediction underestimates the measurement at visibilities lower than 200 $\mathrm{m}$, while overestimates it for visibilities higher than $200 \mathrm{~m}$ for $14.5 \mathrm{GHz}$.

The proposed model produces reliable predictions by considering dust storm intensity variations along the propagation path. The 2-D structure of the dust storm has constituted a base to develop the reduction factor, a ratio that estimates the portion of the link covered by the storm. Since the path lengths of 6.2 and $7.6 \mathrm{~km}$ are much shorter than the assumed dust cell structure, the proposed reduction contributes significantly to prediction in longer path lengths.

\section{CONCLUSION}

All contemporary dust storm attenuation models predict in $\mathrm{dB} / \mathrm{km}$ by considering that the dust storm is uniformly distributed across the microwave link. However, it was observed that the dust intensity varies with the distance, which affects total attenuation, and this issue needs to be addressed in prediction modelling. Based on the proposed 2-D visibility structure of the dust storm, a reduction factor is developed in this paper to accommodate dust storm intensity variations for longer links.

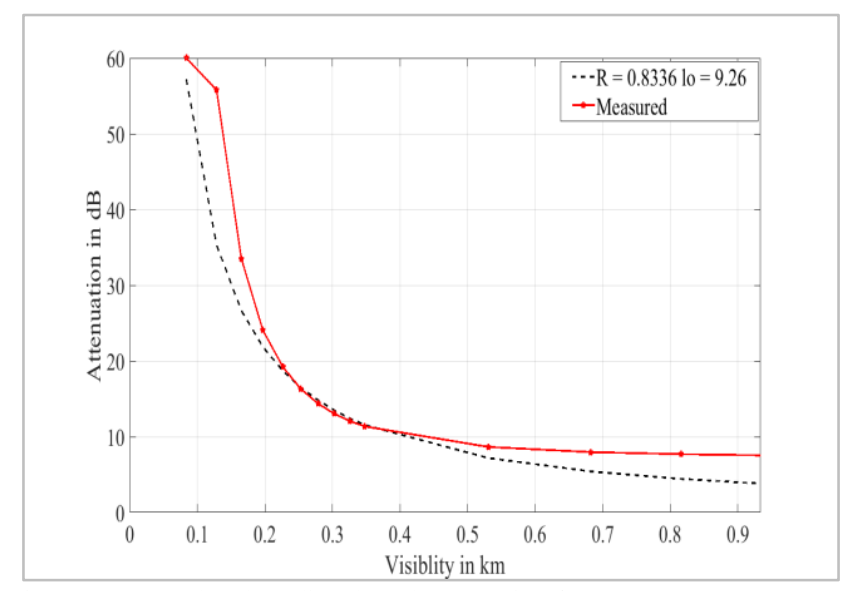

Fig. 9. Measured and predicted total attenuation for MABLOOL - JAREEF SHARIG $6.2 \mathrm{~km}$ link operating at $21.2 \mathrm{GHz}$.

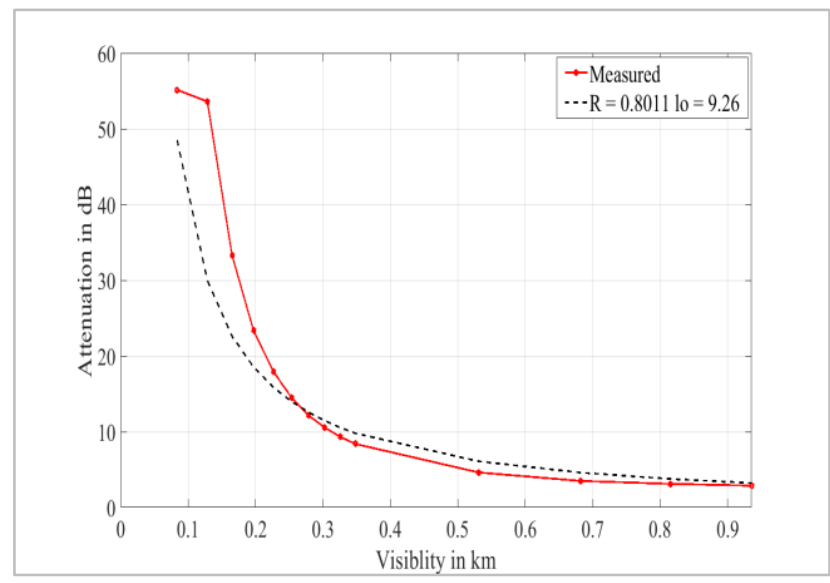

Fig. 10. Measured and predicted total attenuation for BIA-2-MANCHIA $7.6 \mathrm{~km}$ link operating at $14.5 \mathrm{GHz}$.

A novel total attenuation prediction model is proposed by introducing an effective distance with an empirical specific attenuation model reported in an earlier published paper in IEEE Transaction [12]. The effective distance is defined as the product of the actual path length of the microwave link and the reduction factor. The proposed novel total path attenuation model is validated by the measured total attenuation of microwave links operating at $21.25 \mathrm{GHz}$ and $14.5 \mathrm{GHz}$, with a $6.2 \mathrm{~km}$ and $7.6 \mathrm{~km}$ path length and found good agreement

\section{REFERENCES}

[1] A. Musa, S. O. Bashir, and A. H. Abdalla, (2014), Review and assessment of electromagnetic wave Propagation in sand and dust Storms at Microwave and Millimeter Wave Bands --- Part I. In Electromagnetics Research M.[online] vol. 40, pp. 91-100, Available: http://www.jpier.org/PIERM/pier.php?paper=14102904

[2] S.O. Bashir ; N.J. McEwan(1986), Microwave propagation in dust storms: a review, IEE Proceedings $\mathrm{H}$ - Microwaves, Antennas and Propagation.[online] vol.133, pp.241-247, https://ieeexplore.ieee.org/document/4642910

[3] Ishimaru, A. (1977). Theory and application of wave propagation and scattering in random media. Proceedings of the IEEE.[online]vol.65. pp 1030-1061..Avilable https://ieeexplore.ieee.org/document/1454881

[4] Z. A. Shamsan, M. Alammar, A. Aldahmash, A. Alharithy, K. AlSunae, and A. M. Al-Hetar, (2019) Micrometer and millimeter wave P-to-P links under dust storm effects in arid climates.In Engineering, Technology and Appllied Scince Research.[online] vol. 9, no. 4, pp. 4520-4524,Available: https://www.etasr.com/index.php/ETASR/article/view/2972/pdf

[5] T. S. Chu,( 1979). Effects of sandstorms on microwave propagation. Bell System Technical Journal.[online] vol. 58, issue 2 pp. 549- 55, Available:http://ieeexplore.ieee.org/stamp/stamp.jsp?tp=\&arnumber= 6770986

[6] A. S. Ahmed, et al(1987). Airborne Dust Size Analysis for Tropospheric Propagation of Millimetric Waves into Dust Storms. IEEE Transactions on Geoscience and Remote Sensing [online].vol. GE-25, pp. 593-599. http://ieeexplore.ieee.org/stamp/stamp.jsp?tp=\&arnumber $=4072690$

[7] Z. E. O. Elshaikh and M. Islam,(2009), Mathematical model for the prediction of microwave signal attenuation due to dust storm,Progress In Electromagnetics Research M.[online] vol. 6, pp. 139-153, Available: http://www.jpier.org/PIERM/pier.php?paper=09021906

[8] S. M. Sharif.( 2015, June). Attenuation properties of dusty media using Mie scattering solution. Progress In Electromagnetics Research M. [online] vol. Vol. 43, pp. 9-18. Available: http://www.jpier.org/PIERM/pierm43/02.15022403.pdf

[9] D. Xiao-Ying, et al(2011). Microwave and Millimeter-Wave Attenuation in Sand and Dust Storms. IEEE Antennas and Wireless Propagation Letters. [Online]. vol. 10, pp. 469-471, Available: http://ieeexplore.ieee.org/stamp/stamp.jsp?tp=\&arnumber=5770171 
[10] H. Y. Chen and C. C. Ku.(2012).Calculation of Wave Attenuation in Sand and Dust Storms by the FDTD and Turning Bands Methods at 10-100 GHz. IEEE Transactions on Antennas and Propagation[online] vol. $60, \quad$ pp. 2951-2960. Available: http://ieeexplore.ieee.org/stamp/stamp.jsp?tp=\&arnumber=6183464

[11] J. Goldhirsh, (2001).Attenuation and backscatter from a derived twodimensional duststorm model. Antennas and Propagation, IEEE Transactions. [online] vol. 49, pp. 1703-1711, Available http://ieeexplore.ieee.org/stamp/stamp.jsp?tp=\&arnumber=982449.

[12] Elfatih A. A. Elsheikh et al, (2017) Dust Storm Attenuation Modeling Based on Measurements in Sudan. In IEEE Transactions on Antennas and Propagation [online]. Vol.65 pp 4200-4208, Available: https://ieeexplore.ieee.org/document/7948717.

[13] Elfatih A. A. Elsheikkh, et al., "Development of An Empirical Model for Dust Storm Attenuation Predictions," in Proc(ICCCEEE),2019,pp.1-4

[14] Abdulwaheed Musa and Babu Sena Paul ,2020) Dust Particles' Permittivity in Microwave Signal Propagation: A Review.In Journal of communications. [online]vol.15,no.1pp.38-44,Available: http://www.jocm.us/uploadfile/2019/1212/20191212022255165.pdf

[15] E. I. Eltahir, et al., "10 GHz investigation of Sudanese dust event particle characteristics," in Proc(ICCCEEE),2019,pp.1-6.

[16] Elfatih A. A. Elsheikh et al,(2019)Analysis of Airborn Dust effects on Terresterial Microwave Propagation in Arid Area.[online].vol.8 pp 1014-1021,Aviailable: ttp://beei.org/index.php/EEI/article/view/1528

[17] Z. A. Shamsan,(2109) Dust Storm and Diffraction Modelling for 5G Spectrum Wireless Fixed Links in Arid Region. I n IEEE Access [online],vol.7,pp 162828-162840, Available: https://ieeexplore.ieee.org/stamp/stamp.jsp?tp=\&arnumber $=8892472$

[18] M. R. Islam, et al., "Proposing a horizontal path adjustment factor for microwave link's attenuation prediction based on the analysis of dust storm behavior," in Proc (MICC), 2011, pp. 44-48.

[19] R. R. Rogers, (1976), Statistical Rainstorm Models: Their Theoretical and Physical Foundations, In IEEE Trans. On Antennas and Propagation.[online]vol 24,pp 546-566, Available: https://ieeexplore.ieee.org/document/1141359

[20] Vaisala "Vaisala Transmissometer LT31 RVR with New Eyes," Vaisala., Helsinki, FINLAND, Tech. Rep. Ref. B210416en-C ,Vaisala 2010.

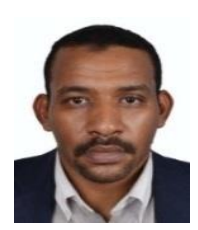

Elfatih Abdelrahman Ahmed Elsheikh received his Bachelor of Science in Electrical and Computer Engineering from Omdurman Islamic University (OIU) Sudan in 2000. He received an MBA from the University of Khartoum (UoK), Sudan, in 2006. Besides, MSc and $\mathrm{PhD}$ both in Electrical Engineering from International Islamic University Malaysia (IIUM) in 2010 and 2017. He is currently working as an assistant professor in the Department of Electrical Engineering, Collage of Engineering, King Khalid University (KKU), Saudi Arabia. He published more than 15 research papers in international journals and conferences. His research interest area is wireless channel modeling, radio link design, RF propagation measurement and modeling.

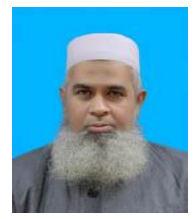

Md Rafiqul Islam received his B.Sc. in Electrical and Electronic Engineering from BUET, Dhaka in 1987. He received his MSc and $\mathrm{PhD}$ both in Electrical Engineering from University of Technology Malaysia in 1996 and 2000 respectively. He is currently working as a professor in the Department of Electrical and Computer Engineering, International Islamic University Malaysia. He has published more than 300 research papers in international journals and conferences. His research interests are antenna design, wireless channel modeling, RF and FSO propagation measurement and modeling. He is a Life Fellow of Institute of Engineers Bangladesh, a senior member of IEEE and member of IET.

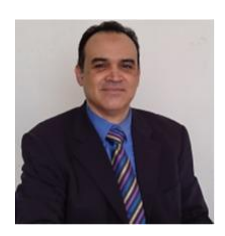

Mohamed Hadi Habaebi (Senior Member, IEEE) received the degree from the Civil Aviation and Meteorology High Institute, Libya, in 1991, the M.Sc. degree in electrical engineering from Universiti Teknologi Malaysia, in 1994, and the Ph.D. degree in computer and communication system engineering from University Putra Malaysia, in 2001. He is currently a full-time Professor at the Electrical and Computer Engineering Department and is the former Head of Department and former Post Graduate Academic Advisor, International Islamic University Malaysia, where he also heads the research works on the Internet of Things. He has supervised many M.Sc. and Ph.D. students, published more than 150 articles and papers, and sits on the Editorial Boards of many international journals. $\mathrm{He}$ is actively publishing in M2M communication protocols, wireless sensor and actuator networks, cognitive radio, small antenna systems, radio propagation, FSO link design, wireless communications and network performance evaluation and application of AI and blockchain to RF, Energy and biomedical areas. He is an Active Member of the IEEE and an Active Reviewer of many international journals.

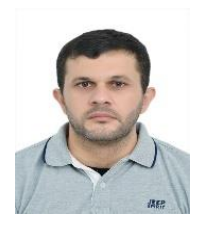

Alhareth Mohammed Zyoud (M'18) received his bachelor degree in electrical engineering from Palestine Polytechnic University in 2006, his master and Ph.D. degrees in communication engineering from International Islamic University Malaysia in 2011 and 2017, respectively. He has authored or co-authored many research papers in international journals and conferences. His current research interests include RF modeling and simulation, 5G radio resource management, and rain attenuation analysis. He is currently working as a part time lecturer at Birzeit University, Palestine.

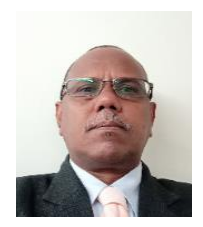

Fakher Eldin Mohamed Suliman Salih (Member IEEE) did his B. Tech in Electrical Engineering (Control). He did both his M. Eng. and $\mathrm{PhD}$ in Electrical Engineering (Communication). Currently, he is an Assistant Professor in the Electrical Engineering Department, College of Engineering, King Khalid University, KSA. He conducts courses for both Bachelor and Master level students. He is the coordinator of ELearning activities in his Department. He is a QM certified Master Course Reviewer for online courses. He published a number of technical papers in ISI journals and international conferences. He is a technical reviewer with ISI and international journals. He has two books under publication process. His research interest includes performance analysis and enhancement for wired and wireless communications systems. His interest also covers the design and analysis of home automation systems and optical switching networks. Dr. Suliman is a member of IEEE, Specialist Engineer in the Sudan Engineering Council, and a full member of the Sudan Engineering Society. 


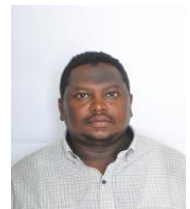

E. I. Eltahir received his Bachelor of Science in Applied Physics (Electronics) from Omdurman Ahlia University (OAU) Sudan, in 2008. He received his $\mathrm{MSc}$ in Communication Engineering from Faculty of Engineering and Technology, University of Gezira, Sudan 2012. Now he is a PhD candidate at karary University. He received his $\mathrm{PhD}$ in Electrical and Electronic Engineering from Karary University Sudan, in 2021. He working as an assistant professor in the Department of Applied Physics and mathematics, Omdurman Ahlia University, Sudan. He published more than 6 research papers in international journals and conferences. His research interest area is radio link design, RF propagation measurement and modelling.

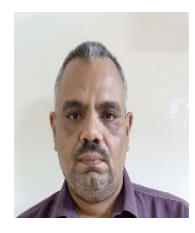

Nadir William Amin received B.Sc in Applied physics and Mathematics from Omdurman Ahlia University, Sudan in 1996. He received his MSc in Mathematics from University of Baghdad, Iraq in 2001. He received his $\mathrm{PhD}$ in Mathematics from University of Bahri, Sudan in 2017. He is currently working as assistant professor in the Department of Mathematics, Collage of Computer Science and Mathematics, University of Bahri. He has researched in applied mathematics science and engineering. 